\title{
Moving toward a prevention strategy for osteoporosis by giving a voice to a silent disease
}

\author{
Karl J. Jepsen ${ }^{1 *}$ DD, Erin M. R. Bigelow ${ }^{1}$, Melissa Ramcharan', Stephen H. Schlecht ${ }^{1}$ and Carrie A. Karvonen-Gutierrez ${ }^{2}$
}

\begin{abstract}
A major unmet challenge in developing preventative treatment programs for osteoporosis is that the optimal timing of treatment remains unknown. In this commentary we make the argument that the menopausal transition (MT) is a critical period in a woman's life for bone health, and that efforts aimed at reducing fracture risk later in life may benefit greatly from strategies that treat women earlier with the intent of keeping bones strong as long as possible. Bone strength is an important parameter to monitor during the MT because engineering principles can be applied to differentiate those women that maintain bone strength from those women that lose bone strength and are in need of early treatment. It is critical to understand the underlying mechanistic causes for reduced strength to inform treatment strategies. Combining measures of strength with data on how bone structure changes during the MT may help differentiate whether a woman is losing strength because of excessive bone resorption, insufficient compensatory bone formation, trabeculae loss, or some combination of these factors. Each of these biomechanical mechanisms may require a different treatment strategy to keep bones strong. The technologies that enable physicians to differentially diagnose and treat women in a preventive manner, however, have lagged behind the development of prophylactic treatments for osteoporosis. To take advantage of these treatment options, advances in preventive treatment strategies for osteoporosis may require developing new technologies with imaging resolutions that match the pace by which bone changes during the MT and supplementing a woman's bone mineral density (BMD)-status with information from engineering-based analyses that reveal the structural and material changes responsible for the decline in bone strength during the menopausal transition.
\end{abstract}

Keywords: Menopausal transition, Bone, Strength, BMD, Osteoporosis, Biomechanics

The optimal management of osteoporosis remains unresolved [1]. Current diagnostic and treatment protocols for osteoporosis are initiated when an individual's areal bone mineral density (aBMD) T-score falls below -2.5 [2]. Those with $\mathrm{T}$-scores between -1 and -2.4 may also be treated depending on whether they have additional risk factors such as a prior fracture or a family history of fractures. With this treatment strategy, one has to become osteopenic or nearly osteoporotic to be diagnosed and treated for osteoporosis. Having to suffer a fragility fracture to be diagnosed and treated for osteoporosis is

\footnotetext{
*Correspondence: kjepsen@umich.edu

'Department of Orthopaedic Surgery, Biomedical Sciences Research Building, 109 Zina Pitcher Place, University of Michigan, Ann Arbor, Ml 48109-2200, USA

Full list of author information is available at the end of the article
}

like having to suffer a heart attack to be diagnosed and treated for heart disease. Fortunately for cardiovascular medicine, adoption of pre-clinical measures such as blood pressure and serum lipoprotein profile and knowledge of major risk factors such as smoking status and obesity allow primary care physicians to treat individuals preventatively in advance of a catastrophic event. Regrettably for bone health, similar pre-clinical measures have not yet been well developed for osteoporosis. The current strategy generally identifies individuals with osteoporosis after they have lost an appreciable amount of bone and prophylactically treats them with the intent of restoring the BMD that was lost during the previous decade. This lagged diagnostic and treatment approach is particularly problematic for women as they uniquely experience the menopausal transition which is

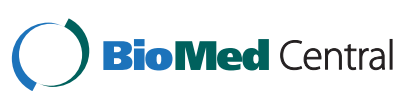

(C) 2016 Jepsen et al. Open Access This article is distributed under the terms of the Creative Commons Attribution 4.0 International License (http://creativecommons.org/licenses/by/4.0/), which permits unrestricted use, distribution, and reproduction in any medium, provided you give appropriate credit to the original author(s) and the source, provide a link to the Creative Commons license, and indicate if changes were made. The Creative Commons Public Domain Dedication waiver (http://creativecommons.org/publicdomain/zero/1.0/) applies to the data made available in this article, unless otherwise stated. 
characterized by more rapid bone loss, thereby positioning them at greater fracture risk during the postmenopause. Further, this strategy is geared toward restoration rather than prevention, and consequently places women at risk of fracturing prior to treatment [2]. In this commentary, we emphasize the need for better prevention methods that include detection of changes in bone strength during the menopausal transition given knowledge of the significance of this life stage for bone health as women transition to old age. This strategy will give a voice to what has often been characterized as a silent disease. However, knowledge gaps remain regarding the ideal window for treatment and the type of information that would be clinically useful for a successful prevention strategy.

Why is the menopausal transition important? To transition the current strategy for treating osteoporosis from one that focuses on restoration toward one that focuses on prevention will require the identification of new biomarkers that monitor a woman's bone health status earlier in life and that identify those women who are in need of early intervention. The menopausal transition is associated with rapid changes in serum levels of folliclestimulating hormone (FSH), estradiol (E2), testosterone, and inhibin $\mathrm{A}$ and $\mathrm{B}$ as well as a rapid bone strength decline before the slower phase of postmenopausal bone loss begins [1,3-8]. Longitudinal studies have shown that accelerated losses in BMD and bone strength begin $\sim 1-2$ years prior to the final menstrual period (FMP), continue at this rate until $\sim 2-5$ years after the FMP, and then slow appreciably thereafter $[1,6]$. Women may lose as much as $33 \%$ of their bone strength between 45 and 65 years of age before treatments for osteoporosis typically begin [9]. The timing and magnitude of bone mass and bone strength changes have been well described on a population average basis [1, 3-8, 10], but little is known about the individual-level differences in bone mass and bone strength during the menopausal transition.

Why do details of bone loss matter? Fracture prone sites like the wrist, spine, and hip are comprised of a relatively thin cortical shell that is supported by a highly organized mass of trabecular bone (Fig. 1). These skeletal structures resemble a bridge, which is comprised of a roadway (cortical bone) and its associated support structure (trabecular bone). Following normal wear and tear associated with daily usage, bits and pieces of the bridge will naturally begin to fail. Imagine one morning a sign is posted indicating there is a $5 \%$ loss in the mass of the bridge and to proceed with caution. Would you drive over the bridge? You would likely want additional information to know whether the $5 \%$ loss in bridgemass included critical features like parts of the roadway or a supporting beam needed to hold up the road. Further, if you wanted to keep the bridge in good shape to avoid a catastrophic event, you would want to know which components were in need of repair and to set up a regular maintenance schedule. We propose that the same concepts for maintaining a bridge are needed to maintain bone strength.

Which details of skeletal changes during the MT matter? To date, risk prediction has focused mainly upon demographic characteristics, family history, medications, lifestyle characteristics (e.g., smoking, alcohol intake), fracture history, and aBMD [11]. aBMD has been used successfully for screening postmenopausal women who have osteoporosis, and identifying large changes in bone mass that may increase a woman's risk of fracturing [2]. However, BMD is not sufficiently sensitive to monitor early declines in bone strength [9], which begin largely during the menopausal transition [1,3]. It has been hypothesized that bone strength may be the more appropriate measure to predict fracture risk $[9,12,13]$. Bone strength is a measure of the amount of load or force it takes to cause a bone to fail, and thus is a critical parameter that differentiates whether a bone will break or not during a simple fall $[12,14]$. However, current treatment paradigms often focus on maintaining BMD not strength. This distinction is important because a woman may lose bone mass without losing bone strength. This phenomenon exists because bone has adaptive features that allow it to compensate for bone loss to maintain strength [15]. Bone forming cells (osteoblasts) can deposit small amounts of tissue on the outer surface of the bone to mechanically offset the loss that occurs when the bone resorbing cells (osteoclasts) remove tissue on the inner surface [16-19]. Thus, bones tend to become wider with aging, a phenomenon that is thought to help maintain bone strength $[16,20,21]$. Because of the way bones are loaded during daily activities, only a small amount of new tissue needs to be deposited on the outer surface to offset a large amount of loss near the inner surface $[21,22]$. Consequently, some women may show a net loss of bone mass while maintaining bone strength. Whether fracture risk depends on the degree to which the newly deposited tissue on the outer surface mechanically offsets the bone loss on the inner surface is not fully understood $[20,23]$. Critically, the amount of new tissue deposited on the outer bone surface declines during the menopausal transition and is only a fraction of premenopausal levels by age 65 [23]. Thus, the window for most efficacious treatment for maintaining bone strength may be during the menopausal transition.

Knowing a woman's bone strength is important, but is not sufficient by itself to inform clinicians on how best to treat women in a personalized preventative manner. The details of how bone changes with aging, in particular the balance between bone resorption and bone formation at all structural levels, are needed to inform 


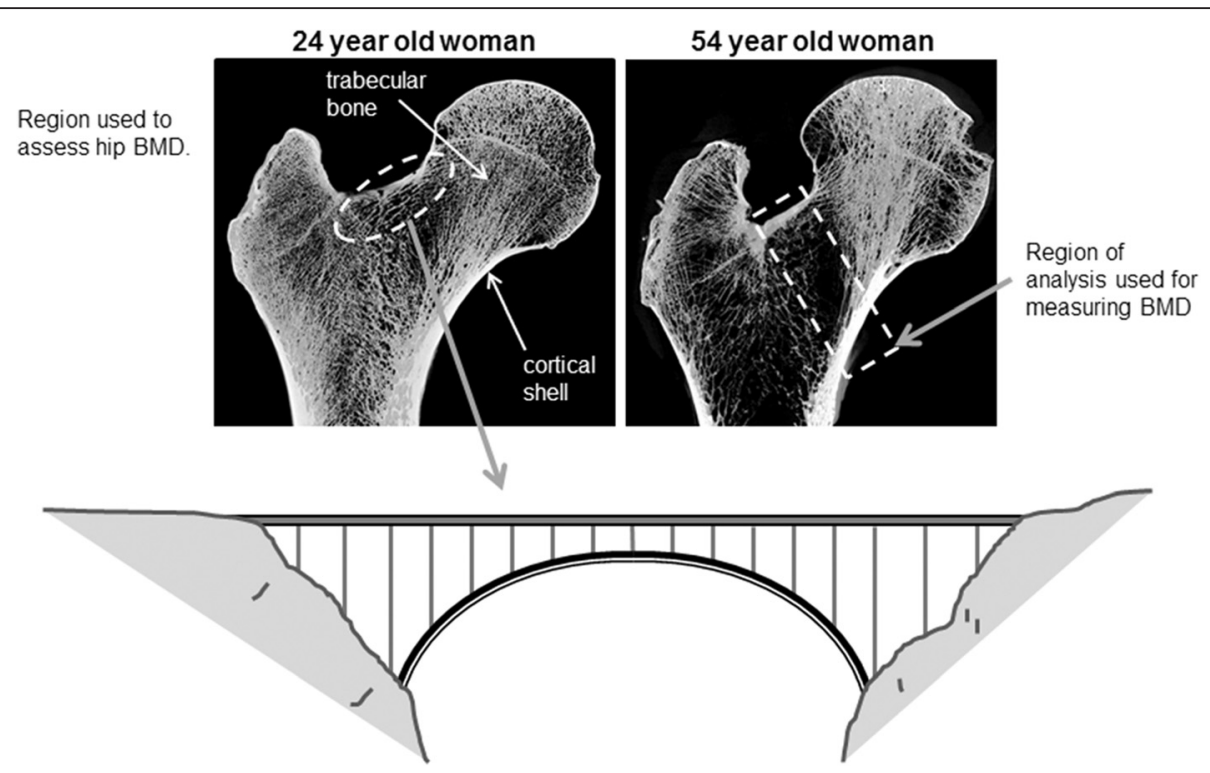

Fig. 1 Sagittal sections derived from 3-dimensional nanoComputed Tomography images (nanotom-s; phoenix|x-ray, GE Sensing \& Inspection Technologies, GmbH; Wunstorf, Germany) of cadaveric proximal femurs for two women, one 24 years old and the other 54 years old, convey how bone loss occurs non-uniformly with aging and predominantly in the region used to measure aBMD with DEXA. Maintaining bone strength is analogous to maintaining a bridge, where all critical structural components must be recognized and targeted to keep the structure intact and functioning to prevent a catastrophic failure event

clinicians how to keep bones strong during the menopausal transition and the postmenopausal years [21,23]. Translational studies are needed to define the different ways in which women lose bone strength. Combining measures of strength with data on how bone structure changes during the MT may help differentiate whether a woman is losing strength because of excessive resorption, insufficient formation, or some combination of these factors. These outcomes may require different treatment strategies to maintain strength [24]. For example, women exhibiting excessive bone resorption may be better treated with an anti-resorptive therapy, whereas a woman with narrow bones and low periosteal expansion may be better treated with an anabolic therapy [25].

The armamentarium of prophylactic treatments for osteoporosis has matured faster than the clinical adoption of technologies that enable physicians to differentially diagnose and treat individuals in a preventive manner. Serum biomarkers of bone resorption and formation are informative of system-wide changes in bone structure, but these biomarkers do not inform on the magnitude and location of bone loss and gain at individual anatomical sites (e.g., femur, distal radius, spine) [26], which is needed to understand how bone strength changed. Periosteal expansion, endocortical resorption, trabecular loss, and increased porosity can all be measured using existing technologies [23, 27-31]. Hand radiographs offer an inexpensive alternative from which bone structural changes can be assessed over time [32-36], possibly beginning at a premenopausal age [22]. The potential costs and apparent impracticality of acquiring structural assessments at multiple time points are recognized deterrents to general adoption of a prevention strategy. However, additional translational research that focuses on understanding how precipitating biological events occurring during the menopausal transition define fracture risk later during the aging process would break the silence of this disease, and potentially identify new technologies, biomarkers, or baseline characteristics that accurately predict individual trajectories of bone loss and gain over time and that can be incorporated into the clinic inexpensively and conveniently.

\section{Conclusions}

Accumulating evidence indicates that there are substantive changes in bone strength during the menopausal transition. Many challenges remain to give a voice to a silent disease by better understanding how events during the menopausal transition affect fracture risk during the postmenopausal years. These include identifying biomarkers that reveal the details of bone loss and gain; identifying individual or combinations of biomarkers that can be used to identify women in need of early intervention; testing whether peripheral skeletal sites (e.g., metacarpals, tibia, wrist) can be used as proxies of strength declines at fracture-prone sites like the proximal femur and spine; understanding how changes in 
hormones affect the balance between bone resorption and formation at all structural levels and how this balance affects strength; and conducting translational studies that identify the mechanisms responsible for inter-individual differences in skeletal aging, particularly during the menopausal transition. Taking advantage of the data within existing longitudinal studies of women transitioning through the menopause, including the Michigan Bone Health and Metabolism Study [37], the Study of Women's Health Across the Nation $[8,38]$, and the Melbourne Women's Midlife Health Project [39], will be extremely helpful in resolving these knowledge gaps and moving from a restoration to a prevention treatment strategy.

\section{Competing interests}

None of the authors have any personal or financial relationships that would affect the presentation of this commentary. One author (KJJ) received an honorarium from Merck \& Co for 2 days of consulting on an unrelated scientific matter. This commentary was not supported by Merck \& Co.

\section{Authors' contributions}

KJJ, EMR, MR, SS, CK-G all contributed to the conceptualization, writing, and editing of this commentary. All authors read and approved the final manuscript.

\section{Acknowledgements}

Research reported in this publication was supported by the National Institute of Arthritis and Musculoskeletal and Skin Diseases of the National Institutes of Health under Award Numbers AR44927, AR065424 and AG024824. The content is solely the responsibility of the authors and does not necessarily represent the official views of the National Institutes of Health.

\section{Author details}

${ }^{1}$ Department of Orthopaedic Surgery, Biomedical Sciences Research Building, 109 Zina Pitcher Place, University of Michigan, Ann Arbor, MI 48109-2200, USA. ${ }^{2}$ Department of Epidemiology, School of Public Health, University of Michigan, Ann Arbor, Ml 48109-2029, USA

Received: 4 August 2015 Accepted: 4 March 2016

Published online: 07 March 2016

\section{References}

1. Sowers MR, Zheng H, Greendale GA, Neer RM, Cauley JA, Ellis J, Johnson S, Finkelstein JS. Changes in bone resorption across the menopause transition: effects of reproductive hormones, body size, and ethnicity. J Clin Endocrinol Metab. 2013;98(7):2854-63.

2. Management of osteoporosis in postmenopausal women. 2010 position statement of The North American Menopause Society. Menopause. 2010; 17(1):25-54. quiz 55-26.

3. Rannevik G, Jeppsson S, Johnell O, Bjerre B, Laurell-Borulf Y, Svanberg L. A longitudinal study of the perimenopausal transition: altered profiles of steroid and pituitary hormones, SHBG and bone mineral density. Maturitas. 1995;21(2):103-13.

4. Heaney RP, Barger-Lux MJ, Davies KM, Ryan RA, Johnson ML, Gong G. Bone dimensional change with age: interactions of genetic, hormonal, and body size variables. Osteoporos Int. 1997;7(5):426-31.

5. Ishii S, Cauley JA, Greendale GA, Danielson ME, Safaei Nili N, Karlamangla A. Ethnic differences in composite indices of femoral neck strength. Osteoporos Int. 2012;23(4):1381-90.

6. Ishii S, Cauley JA, Greendale GA, Crandall CJ, Huang MH, Danielson ME, Karlamangla AS. Trajectories of femoral neck strength in relation to the final menstrual period in a multi-ethnic cohort. Osteoporos Int. 2013;24(9):2471-81.

7. Sowers MF. The menopause transition and the aging process: a population perspective. Aging (Milano). 2000;12(2):85-92.

8. Sowers MF, Crawford SL, Sternfeld B, Morganstein D, Gold EB, Evans D, Kelsey J: SWAN. A multicenter, multiethnic, community-based cohort study of women and the menopausal transition. In: Lobo RA, Kelsey J, Marcus R, editors. Menopause: Biology and pathobiology. San Diego: Academic Press; 2000. p. 175-88.

9. Keaveny TM, Kopperdahl DL, Melton 3rd LJ, Hoffmann PF, Amin S, Riggs BL, Khosla Sl. Age-dependence of femoral strength in white women and men. J Bone Miner Res. 2010;25(5):994-1001.

10. Sowers MF, Karvonen-Gutierrez CA, Yosef $M$, Jannausch M, Jiang $Y$, Garnero P, Jacobson J. Longitudinal changes of serum COMP and urinary CTX-II predict X-ray defined knee osteoarthritis severity and stiffness in women. Osteoarthritis Cartilage. 2009;17(12):1609-14.

11. Kanis JA, Johnell O, Oden A, Johansson H, McCloskey E. FRAX and the assessment of fracture probability in men and women from the UK. Osteoporos Int. 2008;19(4):385-97.

12. Hayes WC, Myers ER, Robinovitch SN, Van Den Kroonenberg A, Courtney AC, McMahon TA. Etiology and prevention of age-related hip fractures. Bone. 1996;18(1 Suppl):77S-86S.

13. Keyak JH, Rossi SA, Jones KA, Skinner HB. Prediction of femoral fracture load using automated finite element modeling. J Biomech. 1998;31(2):125-33.

14. Jepsen KJ, Silva MJ, Vashishth D, Guo XE, van der Meulen M. Establishing biomechanical mechanisms in mouse models: practical guidelines for systematically evaluating phenotypic changes in the diaphyses of long bones. J Bone Miner Res. 2015;30(6):951-66.

15. Karlsson MK, Ahlborg HG, Svejme O, Nilsson JA, Rosengren BE. An increase in forearm cortical bone size after menopause may influence the estimated bone mineral loss-a 28-year prospective observational study. J Clin Densitom. 2015. In press.

16. Smith RW, Walker RR. Femoral expansion in aging women: Implications for osteoporosis and fractures. Science. 1964;145:156-7.

17. Kaptoge S, Dalzell N, Loveridge N, Beck TJ, Khaw KT, Reeve J. Effects of gender, anthropometric variables, and aging on the evolution of hip strength in men and women aged over 65. Bone. 2003;32(5):561-70.

18. Power J, Loveridge N, Rushton N, Parker M, Reeve J. Evidence for bone formation on the external "periosteal" surface of the femoral neck: a comparison of intracapsular hip fracture cases and controls. Osteoporos Int. 2003;14(2):141-5.

19. Kaptoge S, Dalzell N, Folkerd E, Doody D, Khaw KT, Beck TJ, Loveridge N, Mawer EB, Berry JL, Shearer MJ et al. Sex hormone status may modulate rate of expansion of proximal femur diameter in older women alongside other skeletal regulators. J Clin Endocrinol Metab. 2007;92(1):304-13.

20. Albright F, Smith PH, Richardson AM. Post-menopausal osteoporosis. Its clinical features. JAMA. 1941;116:2465-74.

21. Seeman E. Periosteal bone formation-a neglected determinant of bone strength. N Engl J Med. 2003;349(4):320-3.

22. Jepsen KJ, Andarawis-Puri N. The amount of periosteal apposition required to maintain bone strength during aging depends on adult bone morphology and tissue-modulus degradation rate. J Bone Miner Res. 2012; 27(9):1916-26.

23. Szulc P, Seeman E, Duboeuf F, Sornay-Rendu E, Delmas PD. Bone fragility: failure of periosteal apposition to compensate for increased endocortical resorption in postmenopausal women. J Bone Miner Res. 2006;21(12):1856-63.

24. Jepsen KJ, Schlecht SH, Kozloff KM. Are we taking full advantage of the growing number of pharmacological treatment options for osteoporosis? Curr Opin Pharmacol. 2014;16C:64-71.

25. Allen MR, Hock JM, Burr DB. Periosteum: biology, regulation, and response to osteoporosis therapies. Bone. 2004;35(5):1003-12.

26. Lee J, Vasikaran S. Current recommendations for laboratory testing and use of bone turnover markers in management of osteoporosis. Annals laboratory medicine. 2012;32(2):105-12.

27. Duan Y, Beck TJ, Wang XF, Seeman E. Structural and biomechanical basis of sexual dimorphism in femoral neck fragility has its origins in growth and aging. J Bone Miner Res. 2003;18(10):1766-74.

28. Khosla S, Riggs BL, Atkinson EJ, Oberg AL, McDaniel LJ, Holets M, Peterson $J M$, Melton LJ 3rd. Effects of sex and age on bone microstructure at the ultradistal radius: a population-based noninvasive in vivo assessment. J Bone Miner Res. 2006;21(1):124-31.

29. Zebaze RM, Ghasem-Zadeh A, Bohte A, Iuliano-Burns S, Mirams M, Price RI, Mackie EJ, Seeman E. Intracortical remodelling and porosity in the distal radius and post-mortem femurs of women: a cross-sectional study. Lancet. 2010;375(9727):1729-36.

30. Walker MD, Liu XS, Zhou B, Agarwal S, Liu G, McMahon DJ, Bilezikian JP, Guo XE. Premenopausal and postmenopausal differences in bone 
microstructure and mechanical competence in Chinese-American and white women. J Bone Miner Res. 2013;28(6):1308-18.

31. Allen MR, McNerny EM, Organ JM, Wallace JM. True Gold or Pyrite: A Review of Reference Point Indentation for Assessing Bone Mechanical Properties In Vivo. J Bone Miner Res. 2015;30(9):1539-50.

32. Bouxsein ML, Palermo L, Yeung C, Black DM. Digital X-ray radiogrammetry predicts hip, wrist and vertebral fracture risk in elderly women: a prospective analysis from the study of osteoporotic fractures. Osteoporos Int. 2002;13(5):358-65.

33. Dey A, McCloskey EV, Taube T, Cox R, Pande KC, Ashford RU, Forster M, de Takats D, Kanis JA. Metacarpal morphometry using a semi-automated technique in the assessment of osteoporosis and vertebral fracture risk. Osteoporos Int. 2000;11(11):953-8.

34. Gardsell P, Johnell O, Nilsson BE. The predictive value of bone loss for fragility fractures in women: a longitudinal study over 15 years. Calcif Tissue Int. 1991;49(2):90-4.

35. Wishart JM, Horowitz M, Bochner M, Need AG, Nordin BE. Relationships between metacarpal morphometry, forearm and vertebral bone density and fractures in post-menopausal women. Br J Radiol. 1993;66(785):435-40

36. Kiel DP, Hannan MT, Broe KE, Felson DT, Cupples LA. Can metacarpal cortical area predict the occurrence of hip fracture in women and men over 3 decades of follow-up? Results from the Framingham Osteoporosis Study. J Bone Miner Res. 2001;16(12):2260-6.

37. Sowers MR, Wildman RP, Mancuso P, Eyvazzadeh AD, Karvonen-Gutierrez CA, Rillamas-Sun E, Jannausch ML. Change in adipocytokines and ghrelin with menopause. Maturitas. 2008:59(2):149-57.

38. Neer RM, Investigators $\mathrm{S}$. Bone loss across the menopausal transition. Ann N Y Acad Sci. 2010;1192:66-71.

39. Burger $\mathrm{HG}$, Hale GE, Robertson DM, Dennerstein L. A review of hormonal changes during the menopausal transition: focus on findings from the Melbourne Women's Midlife Health Project. Hum Reprod Update. 2007; 13(6):559-65.

\section{Submit your next manuscript to BioMed Central and we will help you at every step:}

- We accept pre-submission inquiries

- Our selector tool helps you to find the most relevant journal

- We provide round the clock customer support

- Convenient online submission

- Thorough peer review

- Inclusion in PubMed and all major indexing services

- Maximum visibility for your research

Submit your manuscript at www.biomedcentral.com/submit

C Biomed Central 